ISSN: 0213-2052 - eISSN: 2530-4100

DOI: https://doi.org/10.14201/shha202139237251

\title{
QUINTO SALVIDIENO RUFO. ALGUNOS APUNTES SOBRE SU BIOGRAFÍA POLÍTICA
}

\section{Quintus Salvidienus Rufus. Some Notes on bis Political Biography}

\author{
Gustavo A. VIVAS GARCÍA ${ }^{1}$ \\ Universidad de La Laguna \\ gusgarvi@gmail.com
}

Fecha de recepción: 8-10-2020 Fecha de aceptación: 27-11-2020

ORCID: https://orcid.org/0000-0002-2820-7199

Salvidienus ist eines der typischen Beispiele jähen Schicksalswechsels aus der Zeit des Kampfes um Caesars wErbe [...].

FRIEDRICH MÜNZER

RESUMEN: La figura del eques romano Quinto Salvidieno Rufo Salvio (cos. des. 39) ha quedado para la Historia de la tardía República romana como el epítome de una carrera política fulgurante que finalizó inopinadamente después de una abrupta caída en desgracia. La suya y la carrera de Cornelio Galo, primer prefecto de Egipto, son semejantes en este y en algunos otros aspectos. Este trabajo tiene como objetivo ofrecer un acercamiento pormenorizado a los hechos que constituyen su apasionante biografía política.

1. Todas las fechas indicadas en este trabajo son antes de la Era, a menos que se indique lo contrario. Agradezco a los profesores Frédéric Hurlet e Isabelle Cogitore sus observaciones sobre el texto. Este trabajo se integra en el proyecto PID2020-113314GB-100: "Antigüedad, nacionalismos e identidades complejas en la historiografía occidental: de la historiografía académica a la cultura de masas en Europa occidental y America Latina (18702020) -ANIHO-». 
Palabras clave: Salvidieno Rufo; caballero; República tardía; Octaviano; historia de Roma.

ABSTRACT: The figure of the Roman knight Quintus Salvidienus Rufus Salvius (cos. des. 39) has remained for the History of the late Roman Republic as the epitome of a resounding political career that ended unexpectedly after an abrupt fall from grace. His and the career of Cornelius Gallus, Egypt's first prefect, are similar in this and in some other aspects. This work aims to offer a detailed approach to the events that constitute his exciting political biography.

Keywords: Salvidienus Rufus; knight; Late Roman Republic; Octavian; Roman History.

La figura del eques romano (Vell. 2,76,4; Suet., Aug. 66,2; Dion 48,33,2) Quinto Salvidieno Rufo Salvio (cos. des. 39) ${ }^{1}$ ha quedado para la Historia de la tardía República romana como el epítome de una carrera política fulgurante que finalizó inopinadamente después de una abrupta caída en desgracia. La suya y la carrera de Cornelio Galo, primer prefecto de Egipto, son semejantes en este y en algunos otros aspectos ${ }^{2}$.

1. Broughton, The Magistrates of the Roman Republic II, 266. El cognomen quizá indique una adopción o la forma estandarizada del mismo: véase a continuación en n. 2 la entrada del Neue Pauly y la del DPRR. Sobre este asunto: Shackleton Bailey, "Two Studies", 1976, 64 y 82, y Syme, Roman Revolution (en adelante RR), 129 n. 2: "Coins of this man struck in 40 B.C. describe him as 'Q. Salvius imp. cos. desig.' (BMC, R. Rep. II, 407). No other authority gives 'Salvius' as his name: had he taken to latinizing the alien gentilicium? or else 'Salvius' is a cognomen". Para el origen social de Salvidieno: C. Nicolet, L'ordre équestre, 1010-1011, n. ${ }^{\circ} 310$ y s. Demougin, L'ordre équestre, 361 y 588.

2. Sobre Salvidieno Rufo puede consultarse la entrada canónica de Münzer sobre el personaje en la Pauly-Wissowa: F. Münzer, s. v. "Salvidienus 4", RE I A2, 1920, cols. 20192021; Costabile, "Salvidieno Rufo", 1985, 357-374; di Stefano Manzella, "Zosimo liberto", 1991, 175-185, en esp. 180; Rohr Vio, "Autocensura e storiografia augustea", 1997, 27-39; id., "Echi di propaganda", 1999, 3-16; id., Le voci del dissenso, 2000; id., "Ex virtute nobilitas coepit, 2004-2005, 19-46; id., Contro il príncipe, 2011; Cogitore, La légitimité dynastique, 2002; Arcaria, Dal senatus consultum ultimum, 2016, 23-79; Pelling, "Salvidienus Rufus, Quintus Salvius, Roman commander,, OCD, online, 2016; acceso el 5 de julio de 2020; Fündling, Jörg et al., "Salvidienus", Der Neue Pauly; y la entrada para "Salvidieno Rufo" en la DPRR (Digital Prosopography of the Roman Republic): http://romanrepublic.ac.uk/ person $/ 2788 /$ ?era_to $=\&$ tribe $=\&$ nomen $=$ salvidiena $\& f=\& r e \_n u m b e r=\& \operatorname{cognomen}=\& n=\& q=\&$ facet_view=person_search\&era_from $=\&$ other_names $=$ \&page $=1 \&$ praenomen $=$, acceso el 5 de julio de 2020. Sabemos que, al menos, la hija de Salvidieno contrajo matrimonio dentro de la aristocracia: F. Münzer, s. v. "Salvidienus 5", RE I A2, 1920, col. 2021. Otros posibles miembros de su gens: PIR ${ }^{2}$, vol. VII.2: S, 2006, n. ${ }^{\text {os }} 118$ y 119, procónsules de Bitinia bajo Vespasiano, quizá el mismo individuo con dos cognomina; también PIR S 120: L. 
Las primeras noticias de la actividad pública de Salvidieno junto al taimado sobrino nieto del Dictador se remontan al invierno de 45-44, mientras se encontraba con Octavio en Apolonia, lugar donde Julio César, el poderoso tío del joven, lo había enviado para que profundizara en su educación y su adiestramiento militar junto a las tropas que estaban entonces estacionadas en Macedonia ${ }^{3}$, en previsión de la inminente expedición contra los partos (Vell. 2,59,5 y Cic., ad Brut. 1,17,4). Salvidieno actuaba probablemente como enlace entre el joven Octavio y los legionarios estacionados en ese territorio toda vez que el individuo era en esencia un militar, un hombre de armas, un experto comandante de hombres sobre el terreno, como quedó demostrado durante toda su carrera oficial. Volveremos sobre este tema en la parte final de nuestro texto, pero, en nuestra opinión, buena parte de la influencia y preponderancia atesorada por Salvidieno durante su carrera y la razón de la rápida y notoria eclosión de la misma creemos que radica en el hecho de su excelencia y eficiencia en el ejercicio de la milicia, lo que lo convertirá en imprescindible a los ojos de sus diversos superiores. Todo ello unido a una más que probable destreza y ductilidad en las artes de la diplomacia.

Rufo pertenecía por nacimiento al orden ecuestre, pero quizá se haya exagerado la pobreza de sus orígenes (Vell. 2,76,4: natus obscurissimis initiis), cuando muy probablemente sus ancestros familiares, que pueden situarse en el centro de la península italiana, en el país de los vestini, poseían una cierta fortuna proveniente de la explotación ganadera.

A lo largo de las siguientes líneas intentaremos responder a una serie de cuestiones sobre la trayectoria vital del militar y del hombre Salvidieno Rufo. Una de ellas es la siguiente: ¿Realmente el joven Octavio y su "asesor» Salvidieno coincidieron por primera vez en Apolonia en los años antes mencionados o su relación provenía de antes? Y, si es anterior, ¿en qué circunstancias concretas trabaron mutuo conocimiento? En esta, como en otras cuestiones, solo podemos ofrecer respuestas tentativas usando el sentido común. Algunos aspectos de la vida de Salvidieno nos hablan claramente de que nuestro hombre sirvió bajo los estandartes de Julio César en distintas funciones ${ }^{4}$.

Salvidienus Rufus Salvianus, cos. suff. 52 o 61 CE, y legado de Panonia. Sobre las concomitancias entre las carreras de Salvidieno y Galo: Arcaria, 2016; y Vivas García, "El trabajo de Syme", Anabases 33 (2021), 237-247. Sobre sus amonedaciones: Crawford, RRC 1, 528-529, n. ${ }^{\circ}$ 523, 40 B.C.

3. Y también, quizá, para que comenzara a crear un núcleo de seguidores entre los elementos de la milicia.

4. Rohr Vio, 1999, 6. 
Esa presencia de Salvidieno junto a Octavio desde la primera hora habla bien a las claras, creemos, de la confianza que el Dictador depositaba en el general, que le había servido con eficiencia y lealtad en el pasado. Tal y como nos cuentan Apiano (Bell. Civ., 4,85) y Dion $(48,18,2)$ en el enfrentamiento de 42 entre Salvidieno y Sexto Pompeyo en Sicilia, el primero había ideado la construcción de unas embarcaciones cuyo modelo se parecía a las que en su día aparejó Julio César para cruzar el Canal de la Mancha en su campaña contra los britanos de los años 55 y 54. Esta circunstancia parece sugerir la idea de una participación directa de Salvidieno Rufo en esas campañas.

Por otra parte, durante el asedio de Perusa acaecido en el invierno de 41 a 40 (Ap., Bell. Civ., 5,32-49 y Dion 48,14-2-3), y en el que Salvidieno jugó un papel decisivo, se pusieron a prueba distintos métodos de asedio similares a los que César había puesto en práctica en Alesia, una docena de años atrás. En ese contexto de Alesia, Salvidieno bien pudo haber aprendido tales técnicas (César, Bell. Gall., 7,68-84). Como apunta F. Rohr Vio:

La familiarità di Rufo con tecniche belliche specifiche suggerisce infatti una sua pur altrimenti non attestata militanza presso Cesare, precisabile forse anche in una carica di responsabilità e fiducia quale la praefectura fabrum 5 .

Por cierto que en ambos casos, tanto en el Canal de la Mancha como en Alesia, los encargados de tales operaciones fueron los efectivos de la séptima legión, la Fulminata, alojados posteriormente en Campania tras su retiro. Sobre este último dato, volveremos un poco más adelante.

Esa posible asociación de Rufo con el Dictador ya fue sugerida en su momento por la mano maestra de Ronald Syme ${ }^{6}$. Salvidieno, por tanto, sería ya hombre de confianza de César desde los años de sus campañas contra los galos y los britanos y, quizá, también en la guerra civil contra Pompeyo, junto a Publio Ventidio Baso (cos. suff. 43). Una lectura atenta, por cierto, de las carreras de Ventidio y Salvidieno nos habla bien a las claras del progresivo afianzamiento de las carreras de ambos hombres bajo la sombra protectora del Dictador, constituyendo ejemplos

5. Rohr Vio, 1997, 37. Sobre los praefecti fabrum de la Península Ibérica puede consultarse la reciente tesis doctoral de García Sánchez, Praefecti Fabrum Hispaniae, 2017. Agradezco al profesor François Cadiou (Burdeos) esta referencia bibliográfica. En comunicación personal de 3 de agosto de 2020, A. R. Birley propone lo siguiente: «If Salvidienus served in Gaul he presumably served with Antonius--hence his misplaced attempt to court Antony's favour, which he revealed to Octavian».

6. Syme, "Sabinus the Muleteer», 1958, 73-80, en esp. $79=R P$ I, 393-399, en esp. 398. 
paradigmáticos de los nuevos sujetos políticos cuyas carreras, al comienzo de índole marcadamente militar, se afianzaron en estos años finales de la República, llegando en algunos casos a sustituir a la vieja clase dirigente "nella complessa fase di transizione tra il plurisecolare modello repubblicano e la nascente struttura imperiale ${ }^{7}$.

La carrera de Salvidieno fue dilatada y exitosa hasta su abrupto final. Una carrera establecida en base a una lealtad nunca traicionada, en primer lugar hacia Julio César y después hacia su heredero. Unos éxitos logrados gracias a una capacidad y eficiencia poco comunes, especialmente en el plano militar como apuntamos antes, y siempre en estrecha dependencia y a la sombra de las grandes individualidades de la gens Julia.

Esto implica, además, que Salvidieno tenía más edad que Octavio, no sabemos exactamente cuántos años, pero nos aventuramos a pensar que como mínimo una decena de años mayor, si no más. Este dato, que a algunos parecerá baladí, tiene desde nuestro punto de vista gran importancia para comprender qué tipo de relación se estableció entre el joven César y el recio militar proveniente del centro de la bota italiana. Este asunto de la diferencia de edad entre ambos hombres creemos que no se ha puesto de relieve hasta ahora de manera clara en los distintos estudios sobre el personaje ${ }^{8}$. Nosotros pensamos que posee una importancia especial. Durante los años de su influencia casi permanente en el entorno de Octavio, es muy posible que Salvidieno jugara un papel de consejero paternal del joven al que, no lo olvidemos, es probable que conociera por primera vez cuando este era un joven de dieciocho años.

Quizá la primera vez que trabaron relación Salvidieno y el joven que, poco después se convertiría en el heredero de César, fue durante los meses de mayo a agosto de $45^{\circ}$ cuando Octavio, tras convalecer de una breve enfermedad, marchó a Hispania con un conjunto de amigos y personas próximas a Julio César al objeto de unirse a este en la campaña de represalia contra los últimos reductos de resistencia pompeyana en la Península Ibérica ${ }^{10}$. Podemos especular con que, entre la nómina de amigos de César que acompañaron a su joven sobrino en este viaje, probablemente se encontraba Salvidieno. Este sería uno de los tres hetairoi que

7. Rohr Vio 2004-2005, la cita en p. 21.

8. Cf. n. 2 .

9. Sobre todo este periplo: Perea Yébenes, «Julio César y el joven Octavio», 2017, 68106; Rohr Vio, 1999, 6 sitúa el viaje un año antes, en 46.



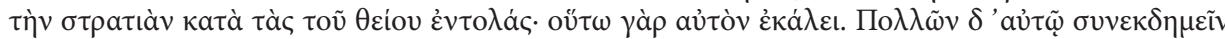



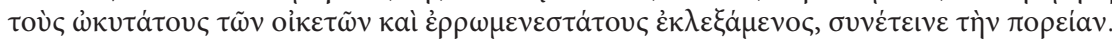


regresaría con Octavio en la nave del Dictador pocos meses después ${ }^{11}$. Por tanto, podemos considerar que ese fue el inicio de la relación entre el futuro Augusto y Salvidieno.

Poco después nos encontramos con los tres hombres: Agripa, Salvidieno y Octavio, en Apolonia. A partir de este momento, el importante papel que a buen seguro jugó Salvidieno en los años siguientes se vio injustamente oscurecido, a nuestro entender, por la influencia cerca de Octavio del más joven e inexperto Agripa, influencia que probablemente fuera menor de lo que siempre se ha venido considerando.

Poco después de la muerte del Dictador, a comienzos de 43, leemos en las cartas del político de Arpino (Cic., Ad Fam., 9,24,1) que un cierto Rufo, seguramente Salvidieno, se encontraba en la Campania llevando a cabo acciones de proselitismo en favor de Octavio entre los veteranos de aquella séptima Fulminata que el militar tan bien conocía ${ }^{12}$. Estas acciones de reclutamiento para la causa de Octavio llevadas a cabo en Campania por el astuto Salvidieno, junto con otros fíloi de primera hora ${ }^{13}$, casi al día siguiente de la vuelta de Octavio a la península itálica; vienen confirmadas por una carta de Bruto a Ático fechada en mayo de 43, donde el primero comentaba hechos acaecidos a finales de 44 e inicios de 43 (Cic. Ad Brut. 1,17,4) ${ }^{14}$. Salvidieno Rufo fue, por tanto, uno de los grandes impulsores de la causa de Octaviano.

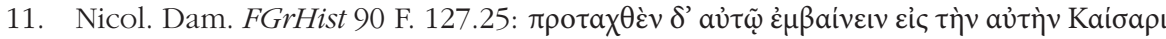

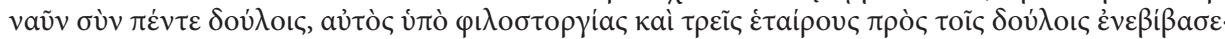

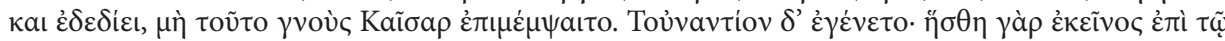

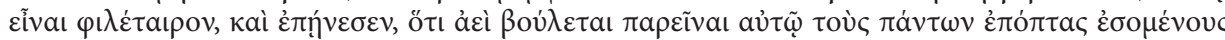

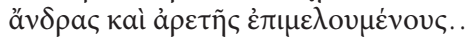

12. Cic. Ad Fam. 9,24,1: Rufum istum, amicum tuum, de quo iterum iam ad me scribis, adiuvarem, quantum possem, etiam si ab eo laesus essem, cum te tanto opere viderem eius causa laborare; cum vero et ex tuis litteris et ex illius ad me missis intellegam et iudicem magnae curae ei salutem meam fuisse, non possum ei non amicus esse, neque solum tua commendatione, quae apud me, ut debet, valet plurimum, sed etiam voluntate ac indicio meo.

13. No es disparatado, creemos, emplear la expresión alemana Alter Kämpfer para referirse a Salvidieno. Como apuntaremos más adelante en la conclusión de estas líneas, quizá sea útil acudir en este caso a la historia comparada, en concreto a los albores del nazismo, repleto de figuras cuya trayectoria política, tan ascendente como fulgurante, presenta varias concomitancias con la biografía de individuos como Salvidieno Rufo, yendo los paralelismos incluso más allá si tenemos en cuenta un ascenso fulgurante acompañado de una abrupta caída. Por supuesto, haciendo todas las salvedades pertinentes.

14. Cic. Ad Brut., 1,17,4: sed redeo ad Ciceronem. quid inter Salvidienum et eum interest? quid autem amplius ille decerneret? 'timet,' inquis, 'etiam nunc reliquias belli civilis. quisquam ergo. 
En enero o febrero de 42, Salvidieno dirigió la flota contra Sexto Pompeyo, que había tomado el control de Sicilia, saqueando las costas itálicas desde esa estratégica cabeza de puente (Livio Per. 117,1; Apiano Bell. Civ. 4,85; Dion 48,18,2-4 y CIL X, 8337, a-g). Rufo fue derrotado en la batalla naval de Regio, principalmente a causa de la inexperiencia de sus propias tropas. Con ocasión de esta operación militar se han recuperado unas glandes plumbeae cerca de la localidad calabresa de Leucopetra. Estos proyectiles fueron utilizados en esta escaramuza militar llevada a cabo por Salvidieno, por encargo de Octavio, al objeto de abortar los proyectos de invasión de la península por parte de Sexto. El nombre de Salvidieno Rufo figura en estos proyectiles junto con las menciones de la salutatio imperatoria que sus tropas le otorgaron, acompañado de la imagen de un fulmen alado ${ }^{15}$. Volveremos a encontrar proyectiles de características similares con el nombre de Rufo en el agro Perusino, lanzados por las tropas de Octaviano contra las de Fulvia y Lucio Antonio con motivo del asedio de Perusa en el invierno de 41-40, hecho en el que Salvidieno tomó parte protagonista. Estas glandes se enmarcan dentro de un circuito propagandístico específicamente diseñado y orientado hacia el elemento militar, donde Salvidieno se encontraba como pez en el agua. En este caso concreto, los proyectiles recuperados cerca de Sicilia y en Perusa nos hablan de una promoción de la imagen del imperator para el consumo de las tropas bajo sus órdenes tanto en el estrecho como en la ciudad perusina.

Poco antes, Salvidieno había sido despachado a Hispania con seis legiones, pero los generales de Antonio le bloquearon el paso en el norte de la península itálica (Apiano Bell. Civ. 5,20) ${ }^{16}$ y tuvo que volver a uña de caballo para hacerse caso del asunto de Perusa sin llegar a pisar la piel de toro en esta ocasión ${ }^{17}$.

Salvidieno capturó y destruyó la localidad de Sentinum y, junto con Agripa, sitió a las fuerzas de Lucio en Perusa. El resto de generales de Marco Antonio, que no tenían una clara cadena de mando para las órdenes que se les proporcionaban, permanecieron el margen de este episodio hasta que el hermano del triunviro fue obligado a rendirse tras varios meses de asedio en el invierno de 40 (Apiano Bell. Civ. 5,24-27-31-35; Dion 48,10,1).

Tras Perusa, Octavio envió a Salvidieno a la Galia para hacerse cargo de un poderoso ejército de once legiones, después del óbito de Fufio Caleno (Vell. 2,76,4; Apiano Bell. Civ. 5,51; Dion 48,20,32). Fue designado

15. Sobre este particular, véase el sugerente análisis de Rohr Vio, 1999, 3-16; esp. 4 y ss.

16. Pelling, n. 2.

17. Gabba, Appiani bellorum civilium liber quintus, 1970, aparato crítico y com. ad. loc. 
cónsul con entrada en el cargo el 1 de enero del año 39, siendo todavía caballero y sin haber alcanzado el rango senatorial. Este hecho constituyó una verdadera anomalía.

El resto es historia conocida. Al albur de los acuerdos de Brindisi, auténtica clave de bóveda y culmen de la componenda triunvira ${ }^{18}$, Marco Antonio habría denunciado a Salvidieno Rufo. Según el triunviro, el antiguo lugarteniente de César y hombre de confianza de Octavio le había sugerido orquestar una suerte de conspiración o maniobra política para excluir al heredero de César de la escena de los acontecimientos. Octavio había convocado entonces de forma inopinada a Salvidieno de vuelta a Roma, justo cuando este estaba a punto de asumir el mando de las tropas de Fufio Caleno (Apiano Bell. Civ. 5,66 y también Bell. Civ. 5,51; Dion $48,20,3)^{19}$.

Tras una conversación privada con su antiguo uomo di fiducia, Octavio había entregado a su amicus a un tribunal formado por miembros del Senado y en la consiguiente sesión del mismo el joven César había realizado personalmente los cargos contra su antiguo lugarteniente. El resultado fue que Salvidieno fue ejecutado por orden del Senado, a instancias de Octavio (Suet., Aug. 66,3; Dion 48,33,3); o bien se suicidó previamente para evitar la ejecución (Liv., Per. 127: mortem conscivit) ${ }^{20}$. De hecho, Livio es el único que indica que se suicidó antes de ser puesto en manos del verdugo. Tras su muerte, se le declaró hostis rei publicae tras sentencia condenatoria por perduellio o maiestas ${ }^{21}$. Se celebraron sacrificios de gratitud en Roma por haber escapado del peligro de la supuesta conjura orquestada por Salvidieno y la Urbs se colocó bajo el control de los triunviros.

En el asunto más complejo y polémico de la biografía política de Salvidieno la tradición, lejos de ser homogénea, parece estar de acuerdo en atribuir a Rufo proyectos políticos subversivos imbuidos de la intención de reemplazar a Octaviano en la escena política de Roma, atribuibles a su ansia por el poder personal, así que no parece haber duda de que la acción y el comportamiento implementados por Rufo entran de lleno en la dimensión criminal del denominado crimen maiestatis. No parece ser un intento genérico de eliminar a Octavio, sino un proyecto articulado de subversión política, como se deduce de Apiano (Bell. Civ. 5,66), que,

18. Vivas García, Octavia contra Cleopatra, 2013, 55-106.

19. Véase en Gabba, 1970; un análisis de este imbroglio.

20. El profesor Pierre Sánchez (Ginebra) me indica atinadamente que un posible suicidio interrumpiría el proceso judicial, pudiendo la familia del acusado conservar sus bienes. Un famoso ejemplo, eso sí, posterior en el tiempo, es el de Cn. Calpurnius Piso Pater, acusado de maiestate bajo Tiberio después de la muerte de Germánico.

21. Sobre este complejo asunto jurídico: Arcaria, 2016, 61-79. 
al ilustrar los preparativos para la acción de Rufo, aclara que la misma debería haber resultado en una deserción concertada con Antonio, lo que habría desembocado en una alianza bicéfala que excluyera de la escena política, probablemente de forma violenta, al heredero de César. Esta lectura digamos tradicional de los hechos reconcilia bien todas las fuentes que conocemos, en relación a los motivos de las negociaciones preliminares con Antonio por parte de Rufo, y parece responder bien a la compleja situación histórica del momento ${ }^{22}$.

Ahora bien, dentro de este marco, en el que Octaviano es visto uniformemente por las fuentes como la víctima del diseño conspirador de Salvidieno Rufo, parecen surgir huellas de una tradición alternativa con respecto a su culpa, ya que, aunque ningún testimonio cuestiona explícitamente sus responsabilidades reales, Apiano y Dion dejan espacios para vislumbrar la posible existencia de una hipótesis sobre la inocencia o la no culpabilidad de Salvidieno ${ }^{23}$.

En el caso del primero, aunque deja claro que fue Antonio el autor de la denuncia contra Rufo, se apresura a enfatizar que la delación de Antonio no obtuvo en absoluto la aprobación general aunque, inmerso en la tradición filoantoniana, se preocupa por justificarlo puerilmente en base a la pretendida bondad del triunviro. En cuanto a Dion, que inicialmente había mencionado el asesinato de Rufo por orden de Octavio usando el

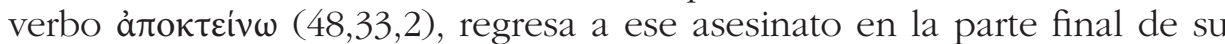
testimonio, usando sin embargo el verbo $\sigma \varphi a ́ \zeta \omega$, que indica exactamente el sacrificio ritual de víctimas humanas. Por lo tanto, Dion parece sugerir una interpretación de la muerte de Rufo no como un acto debido a la justicia, sino como la verdadera inmolación de una persona inocente, a modo precisamente de víctima sacrificial. De hecho, el propio Dion reconduce a continuación la incriminación y el trágico destino de Rufo remitiéndose a lo provisorio y a la incertidumbre inherentes a la condición humana, sin atribuir a las decisiones de Rufo el abrupto final del militar y dejando traslucir sus propias dudas personales acerca de su culpabilidad.

En palabras de una de las más perspicaces estudiosas de este complejo suceso:

le testimonianze di Appiano e Dione paiono quindi conservare traccia di una tradizione, già contemporanea ai fatti, favorevole all'accusato e contraria al perseguimento ${ }^{24}$.

22. Rohr Vio, 2000, 66 y s.

23. O, tomando prestada la expresión de Rohr Vio, ibid., 32, un "partito innocentista". Cf. Rohr, 2011, 28.

24. Rohr Vio, 2000, 68. 
Pudo suceder perfectamente que en 40, tras el renovado acuerdo entre Antonio y Octaviano, Salvidieno Rufo fuera sacrificado en la mesa de negociaciones de Brindisi, cuando Antonio, que en esa coyuntura estaba en una posición de fortaleza en el colegio triunviral, impuso al colega más débil la eliminación de su brazo derecho, que en ese mismo momento estaba al mando de las antiguas tropas de Antonio en el Ródano, garantizando a Octavio en contrapartida la cura urbis, una herramienta esencial para el control de la ciudad de Roma en esta turbulenta fase del triunvirato.

El hecho de que Salvidieno no fuera culpable de las acusaciones que se le imputaban puede deducirse de las circunstancias de la denuncia contra él; del fulminante regreso de Rufo a Roma, y de la conducta respectiva de Antonio, de Octaviano y del propio Rufo. Ya hemos visto, para empezar, que la queja de Antonio se formuló en el marco de los acuerdos de Brindisi, que sancionaron la reconciliación entre los dos triunviros después de los desacuerdos existentes entre ellos a partir de 42. En este clima de inusitada búsqueda de resolución de conflictos, la acción de Antonio puede entenderse prima facie como un gesto de buena voluntad. Sin embargo, esta coyuntura concreta se caracterizó por una falta total de escrúpulos en la lucha política, tanto en el bando de Octavio como en el de Antonio. Si Salvidieno hubiera sido realmente culpable, Antonio se habría aprovechado más de la ventaja de contar entre sus partidarios con el principal colaborador de su colega y antagonista de su causa, en lugar de denunciarlo. Octavio, por su parte y según lo que nos dicen las fuentes, dio crédito a la delación, pero no deja de parecer muy sospechoso que cuestionara la experimentada lealtad de su uno de sus activos de máxima confianza sobre la débil base de la denuncia hecha por su colega triunviral y oponente, puesto que en las relaciones existentes entre los dos triunviros persistía siempre una profunda desconfianza mutua.

La convocatoria de Rufo se hizo de manera repentina, y probablemente sin que Antonio mostrara ninguna prueba, puesto que en caso contrario la tradición lo habría recordado de otra manera. Dado que Rufo regresó sin demora y sin las legiones de las cuales había asumido el mando hacía poco, debe considerarse que estaba al tanto del acuerdo de Brindisi y, por lo tanto, de la recomposición de las heridas entre Antonio y Octaviano. A la luz de todo esto, uno puede imaginarse que, si hubiera sido verdaderamente culpable, ciertamente no se habría rendido a Octaviano sin más, sino que habría intentado implementar el supuesto plan subversivo del que Antonio le acusó, al menos jugándose una última carta usando las legiones que le habían sido asignadas y de las que había tomado o estaba a punto de asumir el mando. 
El rápido regreso de Salvidieno para encontrase con el sobrino del Dictador parece abonar la idea de su inocencia y la denuncia de Antonio parece adquirir sentido solo en el caso de un Salvidieno inocente, cuya eliminación definitivamente habría debilitado a su jefe de filas. La explicación de la conducta aparentemente incomprensible de Octavio en todo este asunto debe buscarse en las consecuencias de la muerte de Rufo, lo que también aclara mejor las razones que empujaron a Antonio a realizar la denuncia ${ }^{25}$. Como vemos, el final de la vida de Salvidieno y las verdaderas razones de su caída en desgracia siguen siendo hoy motivo de diversas especulaciones.

\section{Conclusión}

Como apuntaba recientemente en un encuentro entre colegas celebrado en la isla de Mallorca, son diversas las preguntas y cuestiones que penden en el aire y quedan por dilucidar sobre este interesante y poco conocido personaje del período triunviral. Este intento de poner el foco de una manera un poco más detallada en su biografía política no deja de revelarnos algunas de las lacunae que existen sobre ciertos detalles de su vida y sus logros.

Salvidieno fue un vir militaris de cierta responsabilidad y valía a las órdenes de Julio César. Pero no sabemos todavía exactamente en qué capacidad y qué función precisa realizaba bajo su mando. Puede ser que fuera un praefectus fabrum, pero, ¿qué desempeño y de qué se ocupaba con exactitud en este puesto: era el encargado de la intendencia de la legión, quizá el responsable de lo que hoy conocemos como zapadores o ingenieros? ${ }^{26}$. A día de hoy no lo sabemos de manera nítida.

Por otro lado, y como hemos analizado a lo largo de estas páginas, el papel jugado por Salvidieno ante Octavio fue en muchas ocasiones: Hispania, Campania, Perusa, etc., el de fixer o "conseguidor", un auténtico apafuegos o, más bien, un "facilitador" de la causa de Octavio. Mas propiamente un rol de senior adviser del joven, especialmente en lo que se refería a los asuntos militares. Algo así como un consejero de Seguridad Nacional avant la lettre, una figura similar a la que fueron por ejemplo Brent Scowcroft para Gerald Ford, Zbigniew Brzezinski para Jimmy Carter o el propio Colin Powell para el mismísimo Ronald Reagan. Un hombre de confianza que le asesoraba, en concreto y sobre todo, en asuntos de

25. Rohr Vio, 2011, 29.

26. $C f$. n. 5 . 
índole militar. Por tanto, la diferencia de edad entre ambos hombres se nos antoja esencial para tratar de comprender el tipo de vínculo y relación que forjaron entre ellos: ¿quizá una especie de padre adventicio que guiara a Octavio en estas y otras cuestiones delicadas en estos años de especial turbulencia política y militar? ¿Podría tener este rol jugado por Salvidieno algo que ver con la causa de su pérdida de confianza ante Octavio?

Y, finalmente, y como indicábamos más arriba ${ }^{27}$, quizá sea interesante y provechoso emprender en esta ocasión un útil ejercicio de historia comparada, esbozando una identificación entre los partidarios de primera hora de Octavio y esos partidarios, esos Alter Kämpfer, miembros de la «vieja guardia” que acompañaron a Adolf Hitler desde la primera hora de la génesis de su movimiento totalitario. Esa figura prototípica del Parteigänger que acompaña al líder carismático desde los inicios de la vida pública de este bien podría ser la figura de Salvidieno Rufo en el caso de Octavio. De hecho, esa descripción como amigo del futuro líder y partidario de él desde la primera hora es la caracterización que hace de Salvidieno en su conocido libro Augustus (1972) el escritor nortemericano John Williams, que ganaría con esta obra en 1973 el National Book Award ${ }^{28}$.

Permítasenos desarrollar un poco más nuestra idea sobre este asunto de los "partidarios" de primera hora del líder carismático, independientemente del momento de la Historia que se elija analizar. En el caso del joven César, Salvidieno sería un ejemplo paradigmático. En la Alemania nazi, los «viejos combatientes» del Führer serían esos nacionalsocialistas de primera hora en contraposición a los denominados despectivamente por estos "violetas de marzo", que eran aquellos que se afiliaron de manera oportunista al Partido en marzo de 1933, momento en que, tras la victoria electoral en Alemania, el Reichstag vota otorgar plenos poderes a Adolf Hitler.

Escribiendo sobre la fulgurante trayectoria de Salvidieno, pensaba de modo recurrente en la trayectoria de individuos como, por ejemplo, Emil Maurice (1897-1972) ${ }^{29}$, uno de los primeros miembros del Partido Nacional Socialista Obrero Alemán (NSDAP), de la Schutzstaffel (SS) y uno de los amigos personales de Adolf Hitler desde los primeros tiempos del movimiento. De hecho, Hitler se convirtió en el miembro número 1 de las

27. Vid. n. 13 .

28. Hay traducción al castellano: John Williams, El hijo de César, Pàmies, 2008, traducción de Christine Monteleone. Williams es también conocido por otros relatos de ficción como Stoner y Butcher's Crossing.

29. Existe una reciente biografía sobre el personaje: Bernage, Emil Maurice, 2018. 
SS y Maurice en el número $2^{30}$. La amistad personal entre ambos data al menos de 1919, cuando ambos jóvenes eran miembros del Partido Obrero Alemán (DAP), considerado el antecesor del Partido Nazi. El 9 de noviembre de 1923 tomó parte en el fallido putsch de la Bürgerbräukeller en Múnich, acabando con sus huesos junto a Hitler y otros líderes nazis en la Prisión de Landsberg. Mientras estuvo en prisión con Hitler, Maurice tomó parte activa en la redacción de Mein Kampf y de hecho es mencionado en el libro. Quizá sea un camino que valga la pena explorar.

La misma confianza con el líder y los mismos privilegios de los que gozará Salvidieno desde la primera hora en Apolonia, esa cercanía con Octavio que quizá, como motivo de envidia, fuera la causa última de su inesperada caída, son los que tendrá Maurice ante Hitler cuando el primero entró en conflicto con el Reichsführer-SS Heinrich Himmler a causa de las reglas de pureza racial a las que este obligaba a los oficiales de las $S S$.

Los problemas empezaron en 1935, cuando Maurice tuvo que presentar los detalles de su historia familiar antes de que se le permitiese contraer matrimonio. Todos los oficiales de las SS debían probar su pureza racial, al igual que la de los miembros de su familia, y resultó que Maurice tenía ascendencia judía: Charles Maurice Schwartzenberger (1805-1896), el fundador del Teatro Thalia de Hamburgo, era su bisabuelo. Cuando tuvo conocimiento sobre el asunto, Himmler recomendó que Maurice fuera expulsado de las SS, junto a otros miembros de su familia, pero para su disgusto Hitler acudió en protección de su antiguo amigo, obligando a Himmler a readmitirlo y a hacer una excepción con él y sus familiares como «arios honorarios".

Quizá mirando de soslayo la especial relación personal y de "patronazgo" que se estableció entre individuos como Maurice y Hitler podamos sacar algún tipo de conclusión válida para poder vislumbrar qué tipo de relación pudo fraguarse entre Salvidieno y el joven Octavio. Quizá esta visión comparativa pueda contribuir a apreciar mejor las sutilezas de la relaciones de amistad y clientelares que se pudieron establecer entre las élites del período triunviral.

\section{BibliografÍA}

Arcaria, F. Dal senatus consultum ultimum alla cognitio senatus. Napoli: Satura editrice, 2016.

30. Mientras que Heinrich Himmler, que, en última instancia, acabaría convirtiéndose en el comandante supremo de las SS, era el miembro número 168 de la organización. 
Bernage, G. Emil Maurice: Garde du corps et ami juif de Hitler. Heimdal, 2018.

Broughton, T. R. S. The Magistrates of the Roman Republic II. Reimp., New York: American Philological Association, 1968.

Cogitore, I. La légitimité dynastique d'Auguste à Néron à l'épreuve des conspirations. Roma: École Française de Rome, 2002.

Costabile, F. «Salvidieno Rufo e la legio X Fretensis nella guerra navale fra Ottaviano e Sesto Pompeo (42-36 a.C.)». Rivista Storica Calabrese 6 (1985): 357-374.

Demougin, S. L'ordre équestre sous les Julio-Claudiens. Roma: École Française de Rome, 1988.

Fündling, Jörg y Werner Eck. «Salvidienus», en Der Neue Pauly, editado por Hubert Cancik, Helmuth Schneider (Antike), Manfred Landfester (Rezeptions- und Wissenschaftsgeschichte), acceso el 5 de julio de 2020. http://dx.doi.org/10.1163/1574-9347_dnp_e1028800

Gabba, E. Appiani bellorum civilium liber quintus. Firenze: La Nuova Italia, 1970.

García Sánchez, D. Praefecti Fabrum Hispaniae. Estudio Prosopográfico. Universidad de Alcalá de Henares, 2017, tesis doctoral.

Nicolet, C. L'ordre équestre à l'époque républicaine (312-43 av. J.-C.), 2, Prosopographie des chevaliers romains. Paris: Boccard, 1974.

Pelling, C. B. R. «Salvidienus Rufus, Quintus Salvius, Roman commander». OCD, publicado online en marzo de 2016. DOI: https://doi.org/10.1093/ acrefore/9780199381135.013.5684; acceso el 5 de julio de 2020.

Perea Yébenes, S. «Julio César y el joven Octavio en Hispania en el año 45 a.C. La cuestión del itinerario cesariano y las apelaciones de los saguntinos en Carthago Nova según Nicolás de Damasco, Bíos Kaíoapos, 23-27». Hispania Antiqva. Revista de Historia Antigua XLI (2017): 68-106. DOI: https://doi.org/10.24197/ha.XLI.2017.68-106.

Rohr Vio, F. «Autocensura e storiografia augustea: il caso di Salvidieno Rufo». Prometheus 23 (1) (1997): 27-39.

Rohr Vio, F. «Echi di propaganda política in etá triunvirale: Salvidieno Rufo, la fiamma, il fulmine». Patavium 13 (1999): 3-16.

Rohr Vio, F. Le voci del dissenso. Ottaviano Augusto e $i$ suoi opositori. Padova: Il Poligrafo, 2000.

Rohr Vio, F. «Ex virtute nobilitas coepit: percorsi di affermazione politica nell'età del secondo triumvirato». Atti dell'stituto Veneto di Scienze, Lettere ed Arti. Classe di scienze morali, lettere ed arti 163 (2004-2005): $19-46$.

Rohr Vio, F. Contro il principe: congiure e dissenso nella Roma di AugustoBologna: Pàtron editore, 2011. 
"Salvidieno Rufo". DPRR (Digital Prosopography of the Roman Republic): http://romanrepublic.ac.uk/person/2788/?era_to=\&tribe=\&nomen=salvidiena $\& \mathrm{f}=\&$ re_number $=\& \operatorname{cog}$ nomen $=\& \mathrm{n}=\& \mathrm{q}=\&$ facet_view $=$ person_ search\&era_from $=\&$ other_names $=\&$ page $=1$ \&praenomen $=$

Shackleton Bailey, D. R. Two Studies in Roman Nomenclature (American Classical Studies 3). New York: The American Philological Association, 1976.

Di Stefano Manzella, I. «Zosimo liberto di Q. Salvidieno Rufo e accenso di L. Cornificio console nel 35 A. C.», ZPE 85 (1991): 175-185.

Syme, R. The Roman Revolution. Oxford: Clarendon Press, 1939.

Syme, R. «Sabinus the Muleteer». Latomus 17 (1958): 73-80 = RP I, 393-399. Vivas García, G. A. Octavia contra Cleopatra: el papel de la mujer en la propaganda del Triunvirato (44-30 a.C.). Madrid, 2013.

Vivas García, G. A. «El trabajo de Syme sobre Cornelio Galo publicado en 1938: algunas consideraciones». Anabases 33 (2021), 237-247. 